\title{
Research on the Ecological Conflict between Coastal Wetland and Port Construction-A Case Study of the Meizhou Gulf
}

\author{
Jun Hu',2, Mu Zhang2, Xiang Huang2* \\ ${ }^{1}$ Management School, Jinan University, Guangzhou, China \\ ${ }^{2}$ Laboratory of GIS \& Tourism Information Technology, Shenzhen Tourism College of Jinan University, \\ Shenzhen, China \\ Email: juneloveu@163.com, zhangmu@jnu.edu.cn, ${ }^{*}$ huangxiang@sz.jnu.edu.cn
}

Received 30 April 2014; revised 25 May 2014; accepted 1 June 2014

Copyright $@ 2014$ by authors and Scientific Research Publishing Inc.

This work is licensed under the Creative Commons Attribution International License (CC BY). http://creativecommons.org/licenses/by/4.0/

(c) (i) Open Access

\section{Abstract}

This article is a study on the management of wetland. The future impact of landscape of coastal wetland with the constant changes of human activities is discussed on the basis of the theory and methodology of landscape ecology. Solutions to the contradictions of ecological protection and port construction are put forward.

\section{Keywords}

Ecological Conflict, Wetland Port, Resources and Environment Information System, Meizhou Gulf

\section{Introduction}

Base on the theory of system's point of view, the port construction in coastal areas will doubtlessly contribute to certain impact on the ecology of that area. Therefore, the study of this matter aims to find out ways as for how to improve and maintain the stability of coastal ecosystem in the construction of port. And it is of great significance to study the relations between the ecological protection and the economic activity in a wetland like the Meizhou Gulf that has a poor ecological environment. Besides, "Port city of Meizhou Bay Development Plan" prepared in 2010 defined that the Meizhou Bay will be the region focus on the development in Fujian Province [1], and the port construction projects is under way. In addition to the feasibility study of the port construction from the economics' point of view, the study of the landscape ecology of wetland is also important to the coordinated growth of the economic construction and environmental protection of Meizhou Gulf.

"Corresponding author. 


\section{The Wetland Ecological Environment of Meizhou Gulf}

Meizhou Gulf District, including Putian, Xianyou and Hui'an counties with a large population and insufficient land, is located at $118^{\circ} 27^{\prime} \mathrm{E}-119^{\circ} 22^{\prime} \mathrm{E}$ and $25^{\circ} \mathrm{N}-25^{\circ} 46^{\prime} \mathrm{N}$. The total area is 4703.57 square kilometers; the coast line is $186.57 \mathrm{~km}$ and the land area 2166.13 square kilometers. Along the coast, beach covers 207.04 square kilometer, which is the third largest in the province. The 5-meter-deep sea area is 95.99 square kilometers, the fifth largest in the province. According to the definition of wetland given in Ramsar Convention, water area with the depth of less than 6 meters belongs to wetland. But then in 1974, the USFWS (United States Fish \& Wildlife Supervision) said that deep water area of over 2 meters could not be considered as wetland. They held the opinion that the landscape ecology system of wetland and the landscape system of deep water are continuously distributed. According to the situation in Meizhou Gulf, the definition given in Ramsar Convention and classified by Lu Jianjian (1998) is more applicable [2]. Therefore, Meizhou gulf should be considered as an ecosystem combined with esturaine beach wetland and deep water. Its subsystem can be classified as upper, middle and lower wetland. As port construction is taking place in most parts of the Gulf, this article is therefore covering not only the wetland but also the whole ecological system of the Gulf (see Figure 1).

Meizhou Gulf is a half-closed bay facing the southeast. Stretching from the north to the west and then to the south are Putian, Xianyou and Hui'an counties. The landforms belong to volcanic rocks and tableland of red soil; the south and north banks belong to a coast of slightly-eroded bedrock and the west bank is a coast of mud. The coastline extends a little bit into inland and then meets the wide wetland area. In the whole ecological environment, due to the long time impact of human activities, the existing vegetation has been destroyed and became secondary biocenosis where there is a shortage of surface water. As a result, the vegetation available includes scrub-shrub, grassland and brushwood, etc. The soil in most of the shoals is saline soil and some is red soil in tableland. Owing to the blind exploration in the past, the quality of the ecological environment of coastal wetland has been degraded greatly, resulting in waste of large area of land, destroy of vegetation, serious soil erosion and poor use of land [3]. Therefore, the biomass of wetland here is very low, so are the average resource density and the existing reserves. There are just a few short rivers in this area, such as Mulan, Fengci, Dazhang,

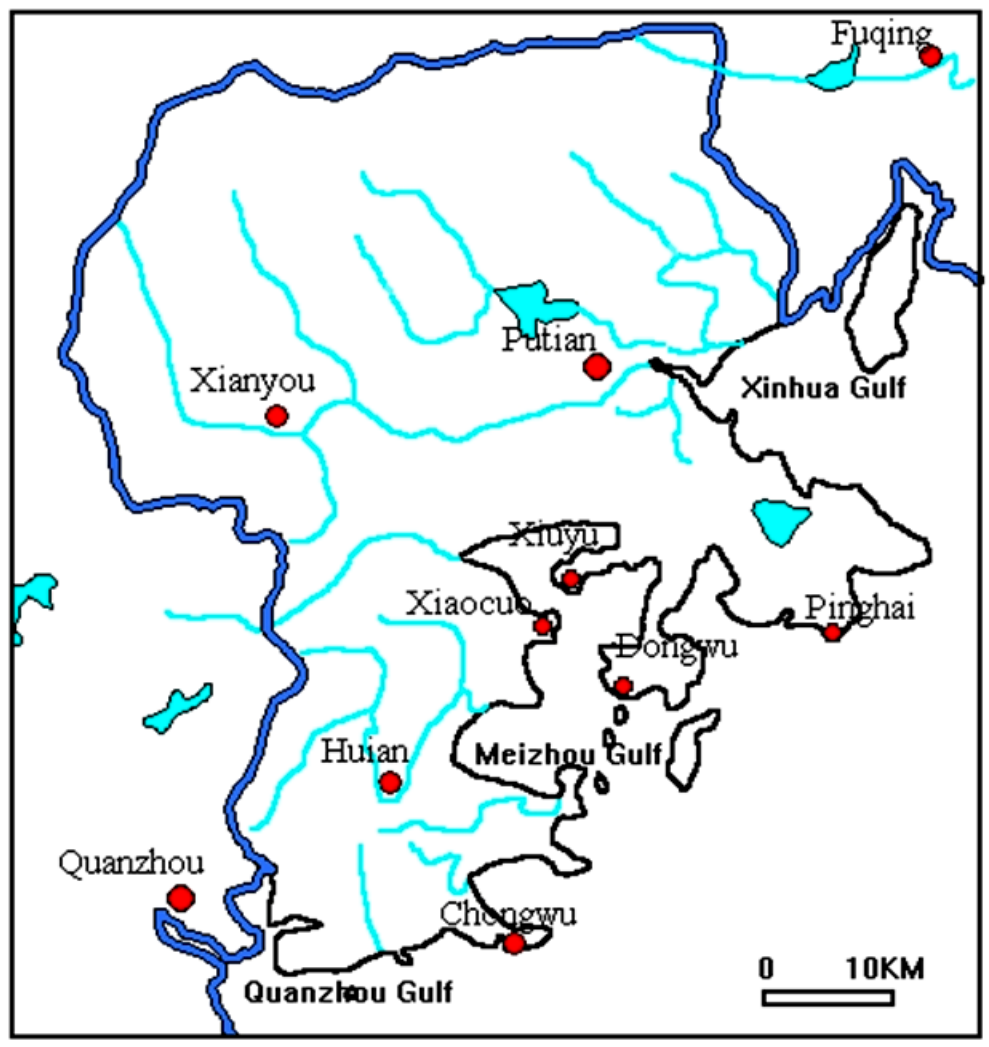

Figure 1. A sketch map of Meizhou Gulf. 
Huangtang Stream and Longjiang River. So water resources are short and spatial distribution of biocenosis is in a free style.

\section{The Structure and Function of Wetland Landscape Ecology System of Meizhou Gulf}

\subsection{Structure of the System}

The structure of wetland landscape ecology system shows the inner constitutions of the system and the results of interrelation and interaction. According to usual practice, the system consists of non-biological elements and biological elements [4]. In Meizhou Gulf, the non-biological elements include matrix (soil, rock bank and shallow area), biological metabolite (sunlight, oxygen, carbon dioxide and inorganic salts), media of biological metabolite (water, air and soil), etc. Through change of physics and chemicals, they affect activities of the biological elements of the system. Biological elements include producers, consumers and reducer, which form the main part of the system of wetland landscape ecology and show the main characteristics of the system through the diversity and heterogeneity of wetland landscape [5]. In the above-mentioned situation, the biomass of wetland landscape in land area is small, the change is small, the system substance and the energy movement are not active. The system has a poor stability and, classified as ecotone, it is easily influenced by human activities [6]. As Meizhou Gulf is a half-closed harbor, the structure of wetland landscape level in the shallow waters is homogeneous, the physical system is stable and the biomass is small. However, due to the acceleration of the port construction, the intensity of disturbance of economic activity to the system will be greater and greater. The wetland landscape in seawater will recover from disturbance slowly as its resistance to disturbance is weak.

\subsection{Function of the System}

The edge effect of wetland landscape leads to a rich biological diversity [7]. At present, the index of biological diversity in Meizhou Gulf is low because human activity disturbs the stability of the system, thus weakening the biological activity in the area as well as the function of the system. Being a supplier in a food chain, the function of wetland landscape ecology system is the exchange of substance and energy [8]. As the tidal current in shallow waters in the west of the Gulf is weak and the changing period of sea is long, the biological activity is restrained. Wetland landscape ecology system is also a buffer blocking and filtering water and land substance and flow of energy. The buffer volume is influenced by the size of the system, vegetation and the content of humus in soil [9]. The rate of interception is also affected by tide's nutrient, acidity and basicity, organism of water, climate and the use of land nearby. Generally speaking, the hinterland of Meizhou Gulf is short of surface water, therefore the intensity of exchange of substance and energy and the function of the system are low. As the landscape ecology systems of both land and water areas in Meizhou Gulf are closely linked, the weakening of the landscape ecology system of land will then affect the stability of the nearby sea landscape ecology system. Besides, the speed and way of the substance and energy of the two systems passing the interface are different, resulting in the weakening of the whole system of landscape ecology in the Gulf.

\section{The Conflict between Port Construction and the Protection of Wetland Landscape Ecology}

\subsection{The Scope of Wetland Ecosystem of Land Narrows}

Port construction will involve tideland enclosure, filling for land construction and bank construction, which will have direct impact on wetland ecology system [10] [11]. The large-scale construction on land affects the environment of the beach and the environment of vegetation, thus narrowing the scope of habitat for saline living beings. Infrastructure and auxiliary constructions take up a lot of land. The influx of large population will affect the ecological system of wetland. And there are impacts from constructions of highway, railway, plants and residential blocks [12]. Besides, as the hinterland is lack of water, the exploration of underground water will also destroy the existing saline environment of the wetland.

Using the view of ecological landscape, port construction will change the land use pattern. The connectivity and homogeneity became higher and then lower the ecological quality of ecosystem, because of the rapid expansion of construction land [13]; Second, the central area of port construction around Dongwu, Xiaocuo and 
Xiuyu, are the peninsular interdigitation. There are similar effect such as lower heterogeneity and biodiversity under over disturbance by human activities.

So, accompanying with the port construction, the effect of the narrow scope of the gulf ecosystem could be described as the following: 1) human disturbance changes the equilibrium and stability of biological circulation and earthly chemistry circulation, especially on the initial input, it changes the direction and velocity of circulation process; 2) heterogeneity, an important role player in ecosystem, could provide group growth relationship among different elements, proceed the rational use of natural resources and prevent the further catastrophe; 3 ) wetland landscape changes would influence the stability of the neighbor land and marine ecosystem.

\subsection{Wetland Landscape Change May Lead to the Diffusion of Pollution}

If urban expands rapidly, the agricultural and green land pitch will keep enough amount to maintain the landscape quality. Now the irrational spatial distribution of industry land had caused more environmental pollution. At present, the Meizhou Gulf Port is under construction and there are only a few industrial facilities along the coast. But survey shows that the intertidal and seabed water quality are polluted by oil. The average oil content of water quality exceeds 79 microgram/liter. The oil content of seabed water quality in the middle tidal area in Xiuyu and Xiaocuo is $215 \mathrm{mg} / \mathrm{kg}$ and $300 \mathrm{mg} / \mathrm{kg}$, respectively. According to analysis, it is caused by the sewage discharge of ships and the pollution produced by the demolishing plants in Xiuyu and Putian. Putian Ship Demolishing Plant has several 10,000-ton ships broken down over the past few years, resulting in serious pollution and damaging the aquaculture in the locality. So, to protect the wetland ecological environment, this plant should improve its techniques. From a long-term point of view, ship demolishing plants should move to the outer bay. The water examination reveals that oil is the main pollution, then comes phosphorus and nitrogen. The inner bay and Xiuyu are more seriously polluted than the other parts. PH, DO, BOD, DDT, Prussiate, Phenolle, As, heavy metals and $\mathrm{BHC}$ can meet the first class seawater standard while $\mathrm{Hg}, \mathrm{Pb}$ and $\mathrm{Zn}$ go beyond the standard.

The marine ecological system is a big system consisting of food chains related to each other. The wetland landscape and deep-water landscape in Meizhou Gulf are continuously distributed. In coastal waters, pollutant produced by port industry and civil facility is the main pollution. After the construction of the port is finished, the growing economic activities such as sewage discharge and oil-spill will pollute some areas resulting in the deterioration of water quality. When the port is put into use, the standard for water quality will be degraded from Class 1 to Class 3. Normally, the remanent current will flow to the entrance of the gulf and will help move floating pollutant outward. However the surface remanent current in the inner Meizhou Gulf is flowing to the southeast, therefore the pollutant will gather in Dongwu and pollutes the area. Although in the north of Liyuwei, current velocity is big and is favorable for the diffusion of pollutant, the remanent current here moves into the bay, and will prevent the diffusion of pollutant. Therefore, it is better to build the oil dock in the south of Liyuwei.

In some words, pollution around gulf may lead to the following results: simple system structure, lower species diversity, fewer organism production and the shift of system circulation.

\subsection{Port Construction Degrading the Stability of Marine Ecosystem}

The terrain in the west of the Gulf slopes gently. The wetland includes the area where the depth is less than 6 meters. The ecological environment of this area is interacted by sea and land. On one hand, as there are no rivers running in, the impact of land on the wetland in water area is small. On the other hand, as the bay is $33 \mathrm{~km}$ in depth, the wetland in water is far away from the mouth of the bay. As there is little exchange of current with outer sea over long period, the contact of sea water and air is affected, and the absorption of oxygen is difficult. When water is polluted, it turns stink and discoloration, thus degrades the quality of water. In most of the time in a year, the wind goes eastwards, when tide ebbs and is disadvantageous to the diffusion of pollutants. Those above facts lead to the decrease of biological diversity in the coastal wetland of Meizhou Gulf. According to a survey (Table 1), in spring in Meizhou Bay, the indicators of nutrients elements such as phosphorus and Silicon are low, and silicates even exhausted. The annual salt density is above 30, the highest in the province. Although it is related to the gulf physical environment the sea ecosystem changes when disturbed by the neighbor land ecological landscape system.

Port construction will change not only the land ecological system, but also reduce the marine ecological system and the diversity of living things in coastal waters. Port construction will also change the route of fish and 
Table 1. Seawater chemical content in Meizhou Gulf.

\begin{tabular}{|c|c|c|c|c|c|}
\hline Item & Layer & Spring & Summer & Autumn & Winter \\
\hline \multirow{2}{*}{$\begin{array}{l}\text { Oxygencontent } \\
\quad\left(\mathrm{ml} \mathrm{O}_{2} / \mathrm{L}\right)\end{array}$} & Surfacelayer & 6.10 & 4.33 & 5.19 & 6.36 \\
\hline & bottom & 5.79 & 4.22 & 5.12 & 6.36 \\
\hline \multirow{2}{*}{$\begin{array}{l}\text { Oxygen saturated degree } \\
\qquad\left(\mathrm{O}_{2} \%\right)\end{array}$} & Surfacelayer & 121 & 96 & 103 & 103 \\
\hline & bottom & 113 & 92.4 & 101 & 103 \\
\hline \multirow{2}{*}{$\begin{array}{l}\text { Phosphatic } \\
(\mu \mathrm{mol} \mathrm{P} / \mathrm{L})\end{array}$} & Surfacelayer & 0.04 & 0.25 & 0.28 & 0.47 \\
\hline & bottom & 0.04 & 0.29 & 0.43 & 0.45 \\
\hline \multirow{2}{*}{$\begin{array}{c}\text { Silicate } \\
(\mu \mathrm{mol} \mathrm{Si} / \mathrm{L})\end{array}$} & Surfacelayer & 0 & 6.50 & 17.20 & 18.10 \\
\hline & bottom & 0 & 5.40 & 16.80 & 19.10 \\
\hline \multirow{2}{*}{ Three kind of inorganic nitrogen ( $\mu \mathrm{mol} \mathrm{N} / \mathrm{L})$} & Surfacelayer & 0.39 & 1.80 & 11.58 & 12.76 \\
\hline & bottom & 0.29 & 1.59 & 12.14 & 12.70 \\
\hline \multirow{2}{*}{$\mathrm{pH}$ value } & Surfacelayer & 8.45 & 8.16 & 8.25 & 8.20 \\
\hline & bottom & 8.44 & 8.17 & 8.28 & 8.21 \\
\hline \multirow{2}{*}{$\begin{array}{l}\text { Alkalinity } \\
\text { (meq/L) }\end{array}$} & Surfacelayer & 2.27 & 2.26 & 2.08 & 2.19 \\
\hline & bottom & 2.32 & 2.31 & 2.15 & 2.32 \\
\hline \multirow{2}{*}{$\begin{array}{l}\text { Salinity } \\
\text { (meq/L) }\end{array}$} & Surfacelayer & 31.45 & 33.96 & 30.69 & 30.42 \\
\hline & bottom & 31.98 & 34.01 & 30.91 & 30.47 \\
\hline \multirow{2}{*}{$\begin{array}{l}\text { Water temperature } \\
\qquad\left({ }^{\circ} \mathrm{C}\right)\end{array}$} & Surfacelayer & 20.78 & 26.69 & 21.45 & 11.22 \\
\hline & bottom & 19.70 & 26.03 & 20.66 & 11.08 \\
\hline $\begin{array}{c}\text { Planktonic flora } \\
(\times 104 \text { individual/cubicmeter })\end{array}$ & & & 1014.94 & 26.10 & 2.83 \\
\hline
\end{tabular}

Source: Table 1, 1980-1990, the resources comprehensive survey of coastal and tideland in Fujian province.

shrimps in coastal waters. Animals and birds will migrate, and aquaculture resource will be destroyed, which will reduce the diversity of living beings to different extents. The construction of dock and embankment may change the velocity of tide and soil and sand will silt. According to fieldwork, a dam has formed in the main channel in the northwest of Meizhou Gulf. At the depth of 4 meters, it is widened by about 1 meter and height is raised by $14 \mathrm{~cm}$ every year. There is tide partition here, and a convergency area of bottom current as well. It is also the main cause to silting. If the proposed enclosure works in Liyuwei can be carried out, the dam will probably be moved southwestwards and there will be more silt in the main channel. If the enclosure works is carried out properly, and the dam is moved to inner bay, the channel will not be blocked. Therefore, the enclosure works in Liyuwei has to be done carefully. As for the regular pattern of tide between Xiaocuo and Xiuyu, the surface velocity of tide rising is smaller than that of ebbing, and bottom velocity is just the opposite, which is unfavorable for sand moving given the bottom flow affects silting. According to the survey, when the on-going construction of enclosure in Nanpu is completed, it will reduce 24,000,000 cubic meters of total amount receiving tidewater and thus decrease the water depth of the section in Xiuyu and Xiaocuo by 4 meters. The dunes in the northwest of Putou will move toward Baishijiao accordingly.

\section{Solutions to the Problem}

\subsection{The Habitats of Wetland Ecological System Need to Be Upgraded so as to Meet the Requirements for Land Use}

The change of the landscape ecology system in Meizhou Gulf is inevitable, because the use of land in large area will change the pattern of the landscape. The existing landscape of Meizhou Gulf is dull, the succession of the ecological system is degenerating, the vegetation coverage of the earth's surface is small and large areas of land are deserted. It is difficult to upgrade the habitats of landscape through natural succession. As the construction of the port disturbs the normal succession and destroys the balance of the succession of habitats, the wetland habitats of landscape ecological system is degenerating at a higher speed than that of natural upgrading. In the course accelerated the construction of the port, wetland habitats that have lost biomass can be developed. It is impossible to recover all the original wetland ecological system because wetland area is becoming smaller and smaller with more land being used for construction. The building of tide barrier and dam also expedites the physics and 
chemical change of the environment. Therefore, upgrading of the habitats is one of the last resorts that can maintain the stability of wetland landscape habitats. The upgrade can be done by means of certain recovery techniques, such as select a new species instead of the original tree population, to maintain the stability of the natural habitats in different stages of succession so as to protect the diversity resource of living beings in different habitats. Meanwhile, it recovers the habitats that have been occupied and damaged by human race through natural upgrading organism. In this way, the contradictions of biology protection and wetland development can be eased up. At present, the wetland habitats of Meizhou Gulf are at the stage of regressive secondary succession. Measures for recovery should be laid out at the time when planning the land for construction. Such land as enclosed beach and intertidal wetland that will not be used for construction should be included in kernel area. Even if they are not the main habitats for creatures under protection, they are source of succession and are potential places for creature protection. If they are destroyed, new organism will be destroyed and habitats will be degraded.

It is suggested here that Shelter-forest belt be built in a proper area, such as Xiaocuo port and Xiuyu port of the northern shore of Meizhou Bay coast, to meet the needs for protection and construction. By protection zone or conservation, it means a given area that may also have limited human activities. So it is different from a natural conservation. In a natural conservation, traditional methods for protection are adopted and some natural habitats are separated and closed and will not be affected by human race. However, a landscape ecology conservation is built to protect certain amount of landscape that will not be used or used limitedly for production. This is possible if only port construction will not affect the function of conservation. As for Meizhou Gulf, the landscape that requires protection includes the existing ecological system, for instance, shallow waters and manmade ecological system such as saltern in the upper wetland, green belt in the construction area, off-fishing area and shelter-belt, etc.

So as to set up conservation for landscape ecology in the following areas so as to maintain the stability of the landscape ecology system in Meizhou Gulf: 1) Setting up shelter-forest in the south of Xiaocuo and Xiuyu, in the north of Dongwu, the purpose of which is to prevent, or weaken the energy flow by strong wind to protect the port construction area and to change the micro-climate; 2) Setting up connective protection zones in the upper wetland of Shanyiao Bay to prevent the substance, energy, biology and of each landscape element from being blocked. There is a natural passage from saltern to its adjacent waters. The protection will be favorable for the natural growth of wetland habitats; 3) Building protection embankment in Dongwu and Xiaocuo where wind is strong to serve as a buffer. Besides, build green belts in the construction areas in Xiuyu, Xiaocuo and Dongwu to reduce torrid effect and air pollution (See Figure 2).

Meizhou Bay port city group includes the Xiaocuo port, Xiuyu port and Soochow port. The main building in port and the area between land and sea overlap, so the construction of ecological protection areas within the port

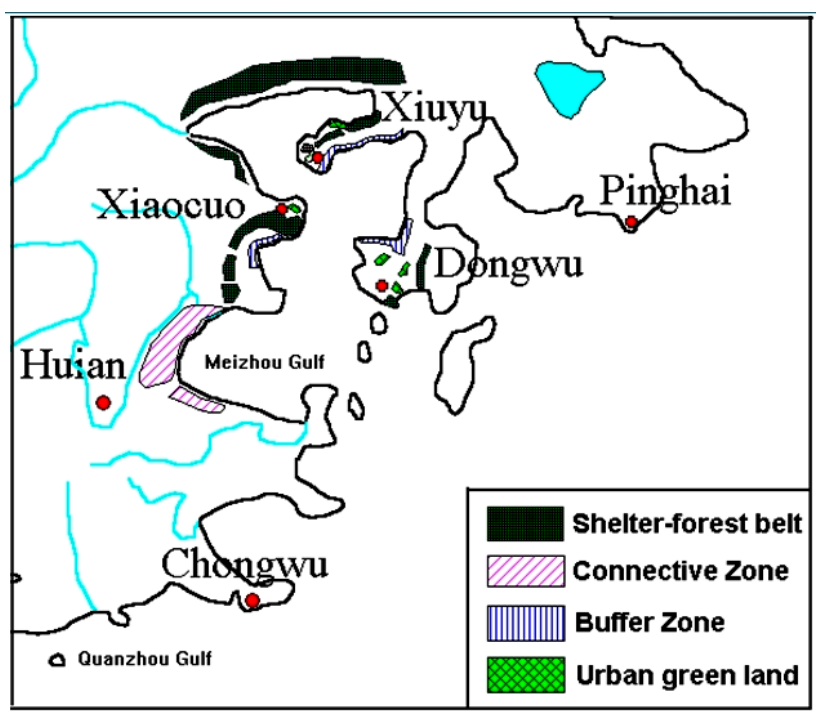

Figure 2. Planning map of landscape ecological conservation. 
land can effectively relieve the impact on port construction to local wetland ecosystem.

\subsection{Monitoring the Wetland Ecology Using (Coastal Wetland Resources and Environment Information System)}

Meizhou Gulf is a newly-built port area. It is clear that land used for the construction will take up much of the wetland habitat. Preparations should be made for the long-term environment protection in addition to the establishment of protection zones. Therefore, it is suggested here that 3S (GIS, GPS, RS) integrated techniques be used to develop coastal resource and environment information system in order to monitor the landscape ecology of wetland.

The coastal wetland factors are complicated and changeable. The biological constitution and the non-biological constitution of the ecological system are changing all the time. Gloabal Positioning System (GPS) makes it possible to locate the wetland accurately and is convenient for survey and data collection. The remote image of Remote Sensing (RS) techniques provides the most essential data for regional landscape analysis and is also the direct means to learn about land use and coverage change. GIS (Geography Information System), with its powerful function of space analysis and data memory, can carry out quantitative analysis and statistics of wetland habitats [14]. As the wetland landscape and the deep-water landscape in Meizhou Gulf are closely related, the analysis of multi-factors and the processing of data are necessary in the research of environmental changes. For example, to simulate the topography of wetland, techniques of spatial numerical value insertion, overlay, fractal simulation and OOP (Object-Oriented Programming) can be adopted [15]. In the research of meteorology and hydrology, the DTM (Digital terrain model) would be set up respectively with the elements on the base of the spatial distributing themselves, such as temperature, precipitation, evaporation, flow of surface water and underground water, tide, waves, content of salt and $\mathrm{pH}$ value. Taking equivalence line and polygon as a storage pattern, these techniques, by the use of overlay, the analysis of buffer, relative analysis and multi-factors analysis, will reveal the space distribution and the space-time development process [16]. GIS can also be used to analyze wetland landscape ecology according to the new theory of wetland landscape ecology [17] [18]. The analysis of vegetation in traditional botany principles is based on the method of sample section. However, GIS can provide omnibearing and large-scaled analyses. If it is used together with remote sensing technique, it can simulate the tendency of vegetation succession of wetland landscape [19]. It can also be used together with Mosaic to combine the characteristics of vegetation with the space distribution of environmental factors such as small climate, soil and hydrology. By using GIS, accurate simulation can be carried out and then descriptions of the ecological system can be obtained [20]. Based on the system's space and attribute database, space analysis function will produce a comprehensive evaluation of wetland habitats so that the goal of wetland ecology protection can be realized.

The concept of CWREIS supported by Areview covers the following points: 1) system database includes basic data, attribute database and space database. The data come from field survey, statistics data of social economy, environmental changes data, maps and remote image, etc. After data is in and being digitalized by Areview, the data will also be stored in its text pattern. 2) The system structure consists of data information source, pre-data processing, applied analysis mold, auxiliary strategy and output. The data managing mold makes it possible to carry out all kinds of operations, to input and output data, to inquire and to add up. The space analysis mold will help carry out space data operation, overlay, buffer analysis, adjoining analysis, classification and visualization. The pattern calculation mold can create new mold and simulation mold of wetland habitat characteristics, such as mold of environment evaluation of wetland, land use and mold of coverage change, so that it can do the analysis of attribute data and mathematical pattern. 3) The function of the system will provide space analysis. For example, discuss the affected area of wetland enclosure on the basis of buffer analysis and study the quality of wetland environment and the distribution of biological diversity. Besides, a comprehensive analysis can also be made on environment and social economy. Therefore, the proposed system function aims to serve the local government as an auxiliary means in resource development and construction programs to ensure coordination between human activity and environmental protection. 4) System actualization: CWREIS will use Visual Basic and Areview of GIS, supported by systems over Window 3.1. As Areview supports different data pattern and other standard pictures, database and texts, it has a complete function of GIS. It can be used for space data management, inquiry, search and space analysis. As for the management of attribute database, use Foxpro. 


\section{Conclusion}

Meizhou Gulf has a complicated environment and ecological system structure. The study of the wetland aims to meet the needs for the construction and development of the port. It can be foreseen that human activity in this area will further affect the whole ecological system of the gulf. When the plan for the development of the port is made, the protection plan should also be considered for the ecological systems of wetland and deep-water habitats. The stability of the ecological system can be maintained by setting up the landscape ecological conservation. The setting up of a resource and information system, CWREIS, on the basis of information technology will make it possible to monitor the change of the coastal habitats.

\section{References}

[1] People’s Government of Putian City, Fujian Province (2010) Port city of Meizhou Bay Development Plan.

[2] Lu, J.J. (1998) Conservation and Research of Wetland in China. East China Normal University Publishing House, Shanghai, 401-409.

[3] The Leading Group of Omnibus Survey on the Coastal and Beach Resources of Fujian Province (1990) The Resources Investigation of Coastal and Beach Area of Fujian Province. China Ocean Publishing House, Beijing, 279-286.

[4] Forman, R. and Godron, M. (1986) Landscape Ecology. John Wiley \& Sons, New York, 146-152.

[5] Xu, H. and Wang, J.J. (1993) The Theory and Application of Landscape Ecology. China Environment Science Publishing House, Beijing, 177-220.

[6] Zhu, H.J. (1997) Sustainable Development and Land Utilization. China Hong Kong Yearbook Press, Hong Kong, 26-33.

[7] Xie, B.G., Li, X.Q. and Cheng, W.M. (1997) The Research about the Theory and Application on Wetland Landscape Ecology. Central South University of Technology Publishing House, Changsha, 20-66.

[8] Mao, Y.W. (1998) The Influence Evaluation about the Ecological Environment. China Environment Publishing House, Beijing, 57-64.

[9] Zheng, D.X. (1997) On Landscape Ecological Protection Area. Scientia Geographica Sinica, 17, 70-75.

[10] Meng, X.M. (1999) Wetland and Globe Environment Change. Scientia Geographica Sinica, 19, 385-391.

[11] Liu, H.Y., Zhao, Z.C. and Lu, X.G. (1999) A Study on Wetland Resources and Protection in China. Resources Science, 21, 34-37.

[12] van Heerden, I.L. (1999) A Comprehensive Management Plan for Coastal Louisiana. Acta Geographica Sinica, 54, 165-176.

[13] Wang, R.S. and Wang, Y.Y. (2000) The Current Situation, Problems and Countermeasures of Wetland Resources in China. Resources Science, 22, 9-13.

[14] Chen, J. and Gon, P. (1998) Practice Geographic Information System. China Science Press, Beijing, 6-9.

[15] Guo, R.Z. (1999) Spatial Analysis. China Wuhan Technical University of Surveying and Mapping Publishing House, Wuhan, 10-34.

[16] Chen, C.S. and He, J.B. (1999) Data Logic Study for the Resources and Environment Information System Design in a Feature-Based Approach. Acta Geographica Sinica, 54, 373-381.

[17] Wang, Y.M. and Liu, C. (1999) Achievements and Challenges of Marine Information System. Resources Science, 21, 75-79.

[18] Zhou, Y. and Wang, S.Q. (1999) The Problems and Countermeasure about Setting Up Land Resources Information System. Journal of Remote Sensing, 3, 71-75.

[19] Huang, H.P. (1999) A Study on Wetland Resources and Environment in Guangdong by GIS. Tropical Geography, 19, 178-183.

[20] Liu, Z.Q., Xu, X.L. and Lu, X.G. (1999) Use of the 3S Technology to Study the Delta Wetland Resources. Geography and Territorial Research, 15, 87-91. 